\title{
Market lingos and metrolingua francas
}

\author{
Alastair Pennycook \& Emi Otsuji \\ Faculty of Arts and Social Sciences \\ PO Box 123 \\ Broadway 2007 \\ NSW \\ Australia \\ Email: alastair.pennycook@uts.edu.au \\ emi.otsuji@uts.edu.au
}




\title{
Market lingos and metrolingua francas
}

\author{
Abstract \\ Drawing on data recorded in two city markets, this paper analyses the language \\ practices of workers and customers as they go about their daily business, with a \\ particular focus on the ways in which linguistic resources, everyday tasks and social \\ space are intertwined in producing metrolingua francas. The aim of the paper is to \\ come to a better understanding of the relationships among the use of diverse \\ linguistic resources (drawn from different languages, varieties and registers), the \\ repertoires of the workers, the activities in which they are engaged, and the larger \\ space in which this occurs. Developing the idea of spatial repertoires as the \\ linguistic resources available in particular places, we explore the ways in which \\ metrolingua francas (metrolingual multilingua francas) emerge from the spatial \\ resources of such markets.
}

Key words: Multilingualism, metrolingualism, markets, repertoires, space, mobility Words: 8475 


\section{The Produce Market: Salamu alaykum mate}

It's a little after 5am. While much of the rest of the city is still asleep in the predawn gloom, Sydney Produce Market is alight and buzzing. As we travel across the dark city in time for the busiest period of the morning, the different rhythms of the city become apparent. Unlike the quiet of the tree-lined suburbs, Oxford Street is alive and noisy, burly dark-clothed bouncers watching night club patrons spilling out onto the pavement. Taxis hover: The night shift changed over at $3 \mathrm{am}$, and fresh drivers are patrolling the streets looking for a late night (for the clubbers) or early morning (for the drivers) ride before public transport gets moving. Early morning garbage trucks are starting up; road workers are closing up after a night job.

Meanwhile, the produce market is humming with activity: Giant trailer trucks stacked high with bananas and other tropical fruit (transported down south from Queensland overnight), or packed with vegetables and stone fruit from Canberra and Shepparton to the south west, or apples from Tasmania even further south, are pulled up alongside loading bays. Their cargoes of fruit and vegetables are whisked away on forklifts. Everywhere forklifts - hundreds of them, lights on, dashing backwards (the forks are loaded too high to drive forwards), turning in tight circles, moving pallets of oranges, onions, pineapples, bananas, beetroot, potatoes from one place to another ${ }^{1}$. This is the largest fresh food market in Australia, and one of the largest in the world. It is estimated that 2,500,000 tonnes of fresh fruit and 
vegetables are sold through this market annually, through the hundreds of wholesalers, produce growers and flower grower-sellers.

Amongst the movements of products and people, Muhibb and Talib are busy:

Excerpt 1 (M: Muhibb, T: Talib, P: Passer-by)

Arabic: Italics; English: plain; (translation in brackets)

(Transcription conventions are provided at the end of the paper)

1. M: Hey! Johnny fix up the stand! Here move these cherry tomatoes put them with them. Let them do it. Let them do Hog's Breath... If you wanna do anything/ if my dad's not doing it start here.

2. T: Ed da calaphak? Etnan?( How much did it cost you? Two?)

3. M: Sorry. Eh tnanan dollar! (Sorry. Yeah two dollars)

[10 second pause]

[talking on mobile phone]

4. T: Good morning! Can you send me one ras one blues please. Thank you very much. See ya buddy! Coles is on special, dollar seventy, dollar sixty on u::mm on on what do you call it, two dollars.

5. P: Salamu alaykum mate (Peace be upon you, mate)

6. M: Wa alaykum assalam (Peace upon you too) 
At their stall on the floor of the giant warehouse - the size of three football pitches Talib and Muhibb are hard at work. The different areas are being set up, pallets of goods piling up for sale. Each area has a portable desk, dropped off and removed by a forklift. This is where the deals are done, the paperwork is shifted, the cash changes hands. On the side of the brothers' desk is a Ramadan calendar. The brothers - second generation Lebanese Australian - are strongly built, hair cut short, beards bulky. In T-shirts and shorts (rather than the traditional leather market aprons some others in the market wear) they are dressed to work. The two brothers run this movable business that comes and goes with the forklifts, with their father and one other brother. They currently have seven other employees of Turkish, Pakistani, Moroccan, Sudanese-Egyptian, Somalian and Philippino backgrounds.

Such interactions are an example of what we have elsewhere (Pennycook and Otsuji, 2014) called metrolingual multitasking, a term we use to capture the ways in which linguistic resources, everyday tasks and social space are intertwined. The seamless management of linguistic resources and interlinked practices are very evident in the above data as the two brothers organize their working area (Line 1) with instructions to their other workers, work out prices (Lines 2 and 3), call suppliers (Line 4), and greet other workers (Lines 5 and 6). The linguistic resources of this workspace are generally drawn from English and Lebanese Arabic, though the two brothers use a considerable variety of styles and registers (modifying both their English and their Arabic according to different customers) and employ both a 
particular local variety of 'market talk' ('one ras, one blues' for raspberries and blueberries $^{2}$ ) as well as a mixture of English and Arabic (Sorry. Eh tnanan dollar!), as do other people in the market (Salamu alaykum mate).

Our aim in this paper is to come to a better understanding of the relationship among the use of such diverse linguistic resources (drawn from different languages, varieties and registers), the activities in which they are engaged, and the larger space in which this occurs. This will entail an exploration of the relation between what we call spatial repertoires (Pennycook and Otsuji, 2014) and metrolingua francas: How do people in complex contexts of diverse linguistic resources draw on the available linguistic resources in a particular place to produce a metrolingua franca that enables communication to occur? This paper therefore seeks to understand the language practices of two markets (the Produce Market complex in one of the largest markets in Sydney and a smaller market - Central Market located in the city) by looking at the interrelationship between language practices, activities and spatial relations.

In doing so, we are not so much concerned with mapping the languages used in the market, nor the impossible task of grasping the entirety of language practices, but with focusing on "mobile resources rather than immobile languages" (Blommaert, 2010, p.197). We are interested in the dynamic ways in which languages, tasks, practices and spaces combine together to produce a metrolingua franca. That these interactions will involve a diverse array of linguistic and other resources we take as 
a given, and while we note with a certain delight the possibility of an Australian/Lebanese Arabic phrase such as 'Salamu alaykum mate' as one worker passes a stall in the predawn business of the Market, we do not intend to emphasize the 'mixing' or 'hybridity' of such language use but rather to take it as the norm (Otsuji and Pennycook, 2014).

Data for this paper are drawn from over 30 hours of observations, recordings and interviews in two markets, which in turn are part of a broader project looking at local language practices in restaurants, cafés, kitchens, market places, construction sites, shops and small businesses in Sydney and Tokyo ${ }^{3}$ (Pennycook and Otsuji, 2014; in press). In both markets - which were chosen to provide a level of comparison between a vast wholesale market that operates before most of the city is awake and a smaller inner-city market that caters for a diversity of customers - a variety of workers were interviewed and, where possible, recorded.

Recordings and interviews, which added to observational data, were transcribed and translated using teams of multilingual researchers. This research takes a linguistic ethnographic approach (Creese and Blackledge, 2011; Rampton, 2007), drawing on the insights of linguistic anthropology but starting above all with language as its focus. Following Li Wei's (2011, p. 1224) 'Moment Analysis', with its shift away from a search for patterns and regularities and its orientation instead towards "spontaneous, impromptu, and momentary actions and performances", we are interested in understanding practices in place, arguing that to understand the 
local language practices of participants we need both ethnography and linguistic analysis.

\section{Metrolingual market repertoires}

Our focus on what we have called metrolingualism draws attention to ways in which language operates in relation to urban space (Otsuji and Pennycook, 2010). Language, Mac Giolla Chríost (2007, p.147) explains, is "fundamental to the appropriation of space and the significance of place in the urban context and this fact has far-reaching implications for both the city and language". Cities we understand as "particularly dense spatial formations containing a complex mix of multiple, heterogeneous social interactions, materialities, mobilities and imaginaries" (Edensor, 2011, p.190). The idea of metrolingual multitasking refers to the ways in which such language use is frequently caught up in a fast-paced multiplicity of activities and cannot therefore be reduced to a functional account of language use in particular domains, where each language can be tied to an activity or interaction (Pennycook and Otsuji, 2014). While much of this is about the pragmatic use of resources to get things done, and while there may not be so much evident 'small talk' (Holmes, Marra and King, 2013) in constructing and maintaining interpersonal relationships in this hectic workplace, there are nonetheless phatic or pleasurable aspects to this play of languages. 
Markets are places where we encounter difference. For Wood and Landry (2008) "the market - both as a concept and a physical location - is central to any understanding of intercultural exchange" (p148). Markets, more than any other city space, perhaps define human engagement with difference, with different people, different clothes, different goods and different ways of speaking. Markets are also a central part of what has been termed globalization from below: These "markets, flows, and trade networks that are part of globalization from below" are part of what Ribeiro (2012, p. 221) calls "the non-hegemonic world system", an alternative to the dominant and homogenizing forces of globalization: "Globalization from below is structured by flows of people, goods, information, and capital among different production centres and marketplaces which, in turn, are the nodes of the non-hegemonic world-system" (p.223).

On the one hand, then, this focus on markets and everyday interactions is part of our interest in what we might call multilingualism from below (by analogy with multiculturalism from below; see Panayiotopoulos, 2010, Wise and Velayutham, 2009). For Wise and Velayutham (2009), multiculturalism from below, or everyday multiculturalism is understood as "a grounded approach to looking at the everyday practice and lived experience of diversity in specific situations and spaces of encounter" (p.3). Rather than top-down approaches to multiculturalism focusing on culture and ethnicity, the attempt here is to get at everyday practices, at the smallscale local encounters of "intercultural 'rubbing along' in the public spaces of the city" (Watson, 2009, p.126). 
On the other hand, a focus on the role of markets within the non-hegemonic worldsystem draws attention to everyday negotiations of value, including languages. Much has been made in recent years of the 'commodification' of languages (Duchêne, 2009; Heller, 2010; Heller and Duchêne, 2011; Park and Wee, 2012), an argument that under late capitalism, we see not only continued capitalist expansion and saturation of markets but also new ways in which language is valued and devalued within new forms of capitalist enterprise. Yet a focus on local language practices and multilingualism from below urges us to question the reification of languages demanded by a language commodification perspective (Block, 2014), and to explore how languages and language practices achieve symbolic value in different fields (Kramsch and Whiteside, 2008).

For people buying and selling in a multilingual market, language is important, but so are the freshness of the zucchini, the price of parsley, the availability of strawberries and the colour of the mangoes (as we shall see). We also therefore need to think not so much in terms of the commodity value of 'languages', but rather the constellation of language practices, local economies, gender relations, discrimination and types of work that lead to the ways in which language practices gain value. Repertoires of linguistic resources gain value in relation to local language practices as much as the wider accrual of value within a global market. We are interested in both multilingualism and markets from below, in the ways in which languages, objects and people rub up against each other in the everyday workings of small trade. 
As part of our exploration of the relations between language and urban spaces such as markets, we have introduced the notion of spatial repertoires, referring to the linguistic resources at people's disposal in a given place (Pennycook and Otsuji, 2014). When we talk of spatial repertoires, we refer on the one hand to a general notion of the relations between semiotic resources and social spaces, and on the other to the specific repertoires of particular places. Rather than looking at language use in such markets in terms of demolinguistic mapping (attempting to map languages and people by area) or interlingual mixtures (talking in terms bilingualism, code-switching, multilingualism or translanguaging), we are here trying to understand local language practices in relation to space and activity (Pennycook, 2010). Blommaert and Backus (2011) argue that in order to understand contemporary linguistic complexities, we need to focus on repertoires as "biographically organized complexes of resources" that, "follow the rhythms of human lives." (Blommaert and Backus, 2011, p.9) rather than concepts of community or competence. While we share with Blommaert and Backus (2011) and Busch (2013) this interest in the historical and social understanding of life trajectories, we also want to bring to the table an understanding of spatiality in the here and now, lest repertoires be seen as only residing in the individual. 


\section{'We understand isfar': lingo-ing at work}

Talib and Muhibb bring to their work their own related though different linguistic repertoires based on their particular histories as Lebanese-Australian market workers. These linguistic resources, however, can only be understood in relation to the practices they engage in (buying, selling, ordering, stacking) and the other linguistic resources that people bring to this space, forming spatial repertoires. From our point of view, then, we need to understand the relations between linguistic trajectories, current activities and spatial repertoires in order to account more fully for the language practices of the market place. They do not necessarily include all and every instance of language use in a place but rather focus on the repeated and regularised language practices of that place. Greetings such as ' $W a$ alaykum assalam' (Peace upon you too) as well as produce such as 'ras' (raspberries) thus become part of this spatial repertoire.

The Produce Market has varied linguistic and produce sections according to various ethnic organizations of space, starting with Lebanese at one end, via Maltese, Italian, Greek, Vietnamese, to Chinese at the other end. Joseph, who runs the two cafés at either end of the vast expanse of fruit and vegetables, gives us insights into local understandings of language practices. The cafés, which open at midnight, provide common breakfast items - burgers, bacon and eggs - but also a mix of other foods: While the café his son runs at the other 'Lebanese' end of the warehouse has more Lebanese food, Joseph's café, at the more 'Chinese' end has a range of other dishes, 
such as wonton soup, satay chicken, Mongolian beef hotpot and so on. The cooks are of Chinese background, the woman making the coffee Korean, the owner Lebanese. English is the first language of the café, but others, especially Arabic and Cantonese, are also in use. This market is where Joseph has always worked - selling vegetables, driving a forklift - since he arrived in Sydney 36 years before: "Well, put it that way, they picked me up from the airport...drove me to the bottom gate down there, and I'm still stuck over here in this maze, I haven't got out of that maze yet!" (Joseph, Interview 08/08/12). His 24-year-old son who "speaks Lebanese, fluent Lebanese with me" but English with his Australian-born Lebanese mother, runs the other café.

This kind of repertoire is common, though with many variations, not only of languages (Cantonese and English, say) but of different mixes of languages: While Talib and Muhibb also bring their mixture of 'Lebanese' and English to the market, their workers from Turkish, Pakistani, Moroccan, Sudanese-Egyptian, Somalian and Philippino backgrounds bring many other linguistic resources into play. While English may be used as a language of some transactions, this also depends on the background of the buyer: "If between a buyer and a seller that is a common language of their background is spoken they do use it, $\mathrm{OK}$, they feel more comfortable they feel more comfortable lingo-ing in their own language" (Joseph Interview). The two dominant languages of the market are Lebanese Arabic and Cantonese, though this varies by area, "Door 1, 2, down to door 5 - very very populated area with Lebanese background people. And they use, very often they use broken English and lingo in Lebanese. Past that area there's no traders of Lebanese people, so we go back to 
different nationalities. Maltese, Italian, Greeks, we go back and use our common language, our first language is English" (Joseph Interview). At weekends it changes too "on a Saturday, it goes back to a different languages, more Italians and Greeks and so on". Meanwhile public signage (see figure 1) - in English, Vietnamese, Arabic and Chinese - suggests a slightly different organization of languages.

Those like Joseph who've been there a long time also get to know a bit of each others' languages: “there's always a jokes about languages, where we pick all the bad words and naughty words. We throw at each other...but not in a nasty way, just ah, a friendly thing, to say, 'yeah I know a little bit about your language and you know a bit about mine'" (Joseph interview). In the two examples below, we see two aspects of this: In the two examples below, we see two aspects of this: On the one hand, Talib adjusts his English to accommodate a customer of Maltese background; on the other we see the same customer of a Maltese background customer intervening in Talib and Muhibb's use of Arabic.

Excerpt 2 (M: Muhibb, T: Talib, CM: Maltese Customer)

1. CM: I am back.

2. T: You are back huh?

3. CM: Lionel talk to you?

4. T: Yeah

5. CM: He say he want more zu [with a strong Maltese accent] 
6. T: Zu::cchi::ni:: [enunciates and prolongs each syllable]

7. CM: Extra extra large... like mine

8. T: No. Extra large like yours no good. [Customer laughs] That's small one [syllable-timed and spoken slowly, mimicking the pronunciation of the customer]

9. CM: How do you know it's a small one!

10. T: Your extra large and my extra large are two different things

In dealing with a customer of Maltese background in the above excerpt, Talib appears to playfully mimic Maltese pronunciation (line 6). He speaks slowly as he enunciates and prolongs the syllables when pronouncing “Zucchini”. The customer's response takes up this humorous exchange in line 7: "Extra extra large...like mine". Talib subsequently appears to imitate - or at least synchronise - the accents as he speaks in English more slowly, with syllable- rather than stress-timing, and with additional syntactic simplifications: "No. Extra large like yours no good” in line 8. Talib's style shifts in English can vary from the contemporary "Yo! Is that mine?” as he shouts to a forklift driver, to the apparently imitative as he deals with a Chinese customer: “No problem mate, No wolly, No wolly mate!'. Metrolingualism, it should be said, is not only about the use of linguistic resources from different languages, but may equally describe those harmonizing (or sometimes parodying) practices of adjustment within codes, as well as certain forms of styling. Indeed, once we start to question the very categories of language that underlie notions such as mono- bi- and multilingualism (Busch, 2013; Otsuji \& Pennycook 2010, 2014), then we need to see how metrolingualism is less dependent on the identification of specifically different 
codes at use at the same time, and more dependent on the integration of diverse linguistic resources in the city.

In excerpt 3, Muhibb and Talib are working out prices and quantities: Arabic is commonly used between them for numbers and quantities, but here it may also have the capacity to conceal their discussions from a customer of Maltese background.

Excerpt 3 (M: Muhibb, T: Talib, CM: Customer)

Arabic: Italics; English: plain; (translation in brackets)

1. M: Shu aloo? (What did he tell him?)

2. T: Arba wa ashreen (twenty four)

3. M: How many boxes does he want?

4. T: Tamana? (eight?) Siteh? (six?) Arba? (four?) Oh four

5. M: Yeah no worries!

6. T: Tell him arba wa ashreen (Tell him twenty four). I told him. He wants to try and get it for cheaper Arba wa ashreen (twenty four) [opening a box of zucchini]

7. Hadol misfareen. Misfareen hadol (These are yellowing. They've gone yellow)

8. CM: Isfar...we understand isfar they are Lebanese (Yellow...we understand yellow) 
9. Isfaree Isfaree Yellow (Yellow, Yellow)

10. T: Get that one and we'll get you another one [to the customer]

Between lines 1and 6, Muhibb and Talib continue to deal with the zucchini order, confirming the number of boxes and price and using English and Arabic resources in a mixture common to second generation immigrants working in such an environment. With other workers on their part of the floor speaking a variety of languages, English and Arabic may be used separately or together, depending on the people with whom they are interacting. In the fast-paced buying and selling, moving and ordering of this space, however, the ways in which they draw on the spatial repertoire may be diverse. As we see in the first three lines, while the numbers are typically in Arabic - Arba wa ashreen (twenty four) - the interactions either side of this exchange can comfortably alternate between Arabic - Shu aloo? (What did he tell him?) - and English - How many boxes does he want?

Here, however, Talib's use of Arabic to acknowledge that the zucchini they are trying to sell have turned yellow (Line 7) - Hadol misfareen. Misfareen hadol (These are yellowing. They've gone yellow) -is picked up by the customer: He knows the meaning of isfar (Liness 8 \& 9). This seems to concur with Joseph's view that they know a bit of each other's languages, though in the case of Maltese and Arabic, this is not wholly surprising (isfar is also the Maltese for yellow). More generally, however, this shows how people draw on their own resources in achieving tasks at hand and how items such as yellow zucchini (the food rather than the linguistic form) play a 
mediating role in the metrolingual action (discussed further below). Metrolingual practices concern the whole package of linguistic resources, personal trajectories and repertoires, objects and space.

This example also shows again the dynamics of action, interaction and transaction as the brothers move around, assess prices and quantities, check the quality of the vegetables and negotiate with this customer. It is to capture this relationship between the linguistic resources - which include varieties of Arabic, varieties of English and a range of mixed code practices (including accent and pronunciations) everyday tasks - the buying and selling of vegetables, the stacking of pallets as orders are filled, the lifting of boxes and updates on supermarket special deals - and social space - the size of their operation within this warehouse, its location around 'Door 2' at the 'Lebanese end', the predominantly male sociality of the customers, workers and cafes - that we focus on metrolingual multitasking and spatial repertoires. With varied linguistic trajectories and repertoires, with diverse possibilities for "lingo-ing", the patterns are always emergent in the local interaction. This is more than "feeling comfortable to lingo in his own background" but is rather the process of management and engagement of linguistic resources as part of wider metrolingual practices involving people, space and vegetables. This metrolingual multitasking then needs to be understood in relation to the spatial repertoires - the available linguistic resources - of this workplace, while any attempt to grasp how a metrolingua franca emerges from this, will have to start from this diversity of interaction. 


\section{'Mat language douh yauh gaa': Central Market metrolingua francas}

Down at the 'Chinese end' of the Produce Market, old 'Uncle Tony' provides a link between the two markets, having started work originally in the old Central Market in 1938, before moving to the Produce Market in the 1970s. When the young Tony started work at the age of 16, the market was mainly "Italian. Italian, Italian. After Italian, the Maltese" (Uncle Tony Interview 09/21/12). As Uncle Tony charts this history of ethnic patterns of migration and involvement in fruit and vegetable growing and selling, we are reminded of Joseph's remarks about the linguistic and ethnic affiliations - "they do lingo in their own language" - that bring people together to buy similar fruit and vegetables from each other.

Eighty percent of market gardeners in the Sydney Basin, as James (2008) notes, are from non-English-speaking backgrounds. Alongside the Chinese are Lebanese, Italian, Maltese, Vietnamese and Cambodian, and these clearly link along trading lines from market gardens to markets, shops and restaurants. For the Chinese in Australia this has a long history, dating back to when former Chinese gold prospectors spread across areas of rural Australia seeking work. By the end of the $19^{\text {th }}$ century there were, according to the locally produced Tung Wah News (東華新 報), about 5000 Chinese market gardeners in New South Wales (of whom about 2000 were around Sydney), making up about two thirds of all market gardeners in the state (Willliams, nd). For both expanding cities such as Sydney, as well as rural 
pastoral and mining concerns, Chinese market gardeners came to play a significant role in the provision of fresh produce (McGowan, 2005).

Chinese in Australia faced multiple discriminations, particularly during the White Australia Policy (Markus, 1979), which is still a clear memory for Uncle Tony: “Not easy to come, you know, before, the White Australian Policies... See it's very hard to come, yeah." It is against this backdrop of discrimination, peripheralization and immigration that the current networks of Chinese vegetable growing and selling needs to be understood. Yet it is also against a more recent history of a growing and increasingly affluent Chinese population, a larger Chinese diaspora across the region, changing food tastes in multicultural Sydney, and the shifting value of Chinese within the politics of symbolic economy and historicity of the city (Leeman and Modan, 2009). Where once Chinese market gardeners loaded their fruit and vegetables for sale in the Central Market - "in their little, little, horse cart - one horse with a cart - and all the fruit in the back. You know" (Uncle Tony Interview $09 / 21 / 12$ ) - now their produce is carried off in white vans to the shops and restaurants in the growing Chinese suburbs to the south. And now it is Cantonese that is frequently used in the Central Market:

Excerpt 4 (FF: female fruit seller, MC: male customer) Cantonese transcription and jyutping transliteration ${ }^{4}$ (English translation in brackets) 
1. FF：呢呢呢呢...係呀, 係呀.呢個色好食.

$\mathrm{ni}^{1} \mathrm{ni}^{1} \mathrm{ni}^{1} \mathrm{ni}^{1} \ldots$ hai ${ }^{6} \mathrm{aa}^{1}, \mathrm{hai}^{6} \mathrm{aa}^{1} \cdot \mathrm{ni}^{1} \mathrm{go}^{3} \mathrm{sik}^{1} \mathrm{hou}^{2} \mathrm{sik}^{6}$

(Look, look, look... yeah, yeah. This colour tastes good)

2. 唔係吃你㗎! $\mathrm{m}^{4}$ hai $^{6}$ aak $^{1}$ nei $^{5}$ gaa $^{2} !$ (I’m not lying to you!)

3. MC: 信你! seon ${ }^{3}$ nei5! (I believe you!)

4. FF：你唔信呢, 就一樣買一隻返去試吓!

nei ${ }^{5} \mathrm{~m}^{4}$ seon $^{3}$ ne $^{1}$, zau ${ }^{6}$ jat $^{1}$ joeng $^{6}$ maai jat ${ }^{1}$ zek $^{3}$ faan $^{1}$ heoi $^{3} \mathrm{si}^{3}$ haa $^{5} !$

(if you don't believe me, then buy one and try it at home)

5. 真係, 越黃啿越好食. 我都想話自己拾返啲去

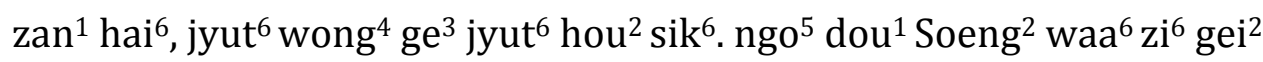

sap $^{6}$ faan $^{1} \mathrm{di}^{1}$ heoi $^{3}$

(Honestly, the more yellow the better the taste. I was just saying I want to take some home to try it)

6. 試吓. 真係㗎,唔係呃你.因為佢呢喺樹熟先

$\mathrm{si}^{3}$ haa $^{5}$. zan ${ }^{1}$ hai ${ }^{6}$ gaa $^{2}, \mathrm{~m}^{4}$ hai ${ }^{6}$ aak $^{1}$ nei ${ }^{5}$ gaa $^{2}$. jan ${ }^{1}$ wai $^{6}$ keoi $^{5}$ ni $^{1}$ hai $^{2}$ syu $^{6}$

$\operatorname{suk}^{6} \sin ^{1}$

(Try it. Honestly, I'm not lying to you. Because these ripen on the tree)

7. MC: 哦...樹上熟 $\mathrm{o}^{2} \ldots \mathrm{syu}^{6}$ soeng $^{6}$ suk $^{6}$ (ohh...ripen on the trees)

8. FF：唔係呃你㗎...真係唔係呃你㗎

$\mathrm{m}^{4}$ hai $^{6}$ aak $^{1}$ nei ${ }^{5}$ gaa $^{2} \ldots$ zan $^{1}$ hai $^{6} \mathrm{~m}^{4}$ hai ${ }^{6}$ aak $^{1}$ nei ${ }^{5}$ gaa $^{2}$

(I'm not lying to you... really I'm not lying to you) 
9. MC: 試吓先 $\mathrm{si}^{3} \mathrm{haa}^{5} \sin ^{1}$ (let's try it then)

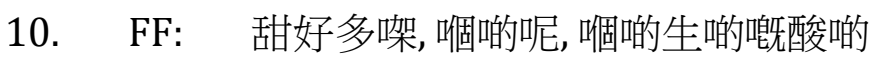

tim $^{4}$ hou $^{3} \mathrm{do}^{1}$ gaa $^{2}$, go di ${ }^{1} \mathrm{ne}^{1}$, go di ${ }^{1}$ saang $^{1} \mathrm{di}^{1} \mathrm{ge}^{3} \operatorname{syun}^{1} \mathrm{di}^{1}$

(it's much sweeter, this one, that one is less ripe and so is very sour)

As with the earlier interactions at the Produce Market, this interaction needs to be understood in relation to the place, the surrounds, the tasks and the type of interaction. At the centre of the action are the mangoes themselves, the fruit that sit between the two interactants and which make up the constant focus of negotiation (including colour, taste, tree-ripening, price). Drawing attention to the interrelated roles of space, language practices, and objects, we are trying to grasp the ways in which individual and spatial repertoires (the language resources people bring with them from their life trajectories and the linguistic resources available to them in particular places), as well as artefacts and objects, form part of the communicative activity of particular places.

This interaction is dominated by the insistence by the fruit seller that she is not lying (Lines 2, 6 and 8), that her mangoes are sweet (Lines 1, 5 and 10), and that she is offering the deal (not much of a deal, in fact) that he can buy them and try them at home (Lines 4 and 5). It matters too that it is the yellowness of the mangoes that is part of their selling point: Unlike the yellowing zucchinis above (which brought he price down), here the ripening from green to yellow is the significant selling point 
(it is also a strategy to avoid having to cut one open to taste it). Unlike the haggling practices identified in markets in Lagos (Ayoola, 2009), the sales pitch here is characterised by two main moves: the insistence on the sweetness of the fruit as evidenced by their yellow colour - 呢個色好食 (This colour tastes good); 越黃嘅越 好食, (the yellower the better) - and the insistence that she is telling the truth - 唔係 呃你...真係唔係呃你 (I'm not lying to you... really I'm not lying to you). There is, then, a constant movement back and forth between the appeal to the colour and taste of the material object and the appeal to the honesty of the seller.

The central question we want to focus on here, however, is where this language use sits within the larger set of multilingual market language use, the spatial repertoires of Haymarket. Here, the customer and seller have settled on a fairly shared code of Cantonese (though hers is a more rural Guangdong variety). In this market, Cantonese is a common language of interaction, and an initial impression from interviews with workers here suggested that English was the default language of commercial transaction, and Cantonese the language of social interaction. This picture, however, needs to be complicated in a number of ways. Mandarin Chinese also plays a role here. Indeed one informant asserted that Mandarin was in fact the lingua franca of the market, though this claim appears to be a result of the widespread use of various Mandarin resources, and this speaker's limited Cantonese resources. The fact that he was able to use Mandarin relatively successfully across the market suggested that it was more widely spoken than seemed to be the case. 
Mandarin Chinese is also a useful language alongside English for selling, and certainly the cheap sales at the end of the day are often done in varieties of English and Mandarin: "One dollar!! One dollar!! Yi kuai quan! Yi kuai quan!". Among the Cantonese speakers, furthermore, there was great variety, including not only Hong Kong and Mainland, rural and urban, but also a range of histories, locations, backgrounds and other language uses. At one fruit and vegetable stall, where we had noted the different Cantonese accents, we discovered that the four women who work there are from Mauritius, Hong Kong, Vietnam and China. Their recognizably different Cantonese styles cannot be reduced to easy labels such as 'Vietnamese Cantonese' but rather reflect the far more complex life trajectories of these women: None of them was simply 'from' these places since all had travelled complex routes, both physically and socially, to end up at this market stall.

While exchanges such as the one above can occur in varieties of Cantonese, and other exchanges may occur in Spanish, Vietnamese, English, Thai and so on, the question we wish to focus on here is what sense can we make of the idea of lingua franca that makes communication more broadly possible across the market. There is a range of workers of other language backgrounds: As a young second generation Lebanese stallholder explained: “Um, I speak a bit of, I dunno, like, Chinese or something" in order to interact with some of those workers and customers. Another worker at a spice stall explained he uses English, Portuguese and Arabic at home (his mother is Portuguese and father Lebanese) but English, Portuguese and Spanish at the market, when Portuguese- and Spanish-speakers come to the stall for 
spices. According to him, there is far less Arabic spoken at this market than Spanish or Portuguese, pointing to the perspectival nature of any understanding of a lingua franca. It is interesting to note, however, that immediately following the interaction above (excerpt 4), two (Latin American) Spanish speakers come into the recorded soundscape by this fruit stall. They are talking to each other (if they bought at this stall, they would presumably use English) which also points to another feature of such linguascapes: It is not only a question of the languages of stall-holders and their transactions with customers but also of all the other languages that customers use in the in-between spaces. Such observations show once again the impossibility of any easy linguistic mapping amid the dynamic metrolinguistic practices of the market.

Another group of workers of Indonesian background - some Hokkien-speaking Chinese Indonesians, others using only Indonesian and English - shed further light on this. It was in conversation with two young men of Indonesian background who were husking corn over a large bin that the situation was perhaps best explained. When asked what languages are used in the market, the response was" セ language 都有㗎!” (mat ${ }^{1}$ language dou ${ }^{1} \mathrm{jau}^{5}$ gaa $^{2}$ - all kinds of languages are spoken here!). The conversation continued in Cantonese:

Excerpt 5 (I: Interviewer, C: Corn husker) 
1. I: 係呀, 咁你自己呢? hai ${ }^{6} \mathrm{aa}^{3}, \mathrm{gam}^{3} \mathrm{nei}^{5} \mathrm{zi}^{6} \mathrm{gei}^{2} \mathrm{ni}^{1}$ ?

(Really! What about yourself?)

2. C: 我呀, 我又福建話, 又印尼話, 又客家話

$\mathrm{Ngo}^{5} \mathrm{aa}^{3}, \mathrm{Ngo}^{5} \mathrm{jau}^{6}$ fuk $^{1}$ gin $^{3} \mathrm{waa}^{6}{ }^{* 2}, \mathrm{jau}^{6} \mathrm{jan}^{3}$ nei $^{4} \mathrm{waa}^{62}$, jau $^{6}$ haak $^{3}$ gaa $^{1}$ waa $^{6 * 2}$

(Me? I speak Hokkien, Indonesian and Hakka)

3. I: 咁勁! gam ${ }^{3}$ ging $^{6}$ (wow!)

4. C: 也都有, 撈埋一齊 $\mathrm{mat}^{1} \mathrm{dou}^{1} \mathrm{jau}^{5}, \mathrm{lou}^{4} \mathrm{maai}^{4} \mathrm{jat}^{1} \mathrm{cai}^{4}$

(all sorts of languages mixed together)

Later on in the conversation, he added Mandarin and English to the list, and since the conversation was in Cantonese, we need to assume this young worker's repertoire includes Hokkien, Hakka, Cantonese, Mandarin, Indonesian and English. Of course, such lists of languages do not tell us a great deal about either the kind of knowledge implied for each language, or the dynamics of interaction in which they are employed. Like the Lebanese-background stallholder's 'Chinese or something', these are loosely identified linguistic resources. The ways in which languages and multilingualism are valued - the value accorded to the Hokkien, Hakka, Cantonese, Mandarin, Indonesian and English repertoire of the corn-husker - need to be understood not so much through an analysis that assumes a priori infrastructural determinants of capital and thereby accepts the logic of commodification by market forces to attribute value to languages, but rather through an analysis that takes 
language practices and their regulation, linguistic identification and exclusion, as crucial to the ways in which value and symbolic capital are distributed.

More interesting than this listing of languages or accounting of values attributed to linguistic resources is this young man’s observations first that “也 language 都有㗎 !” (all kinds of languages are spoken here!), and second that these are “也都有，掞埋 一齊” (all sorts of languages mixed together), for this comes closer to our understanding of how such markets, such everyday multilingualism, actually operates. Rather than trying to map languages by place, person or percentage, what we actually need to appreciate is the metrolingua franca of such environments, the dynamic multilingualism that emerges in all those moments of metrolingual multitasking that make up the daily interactions with a range of people. There are many languages - or linguistic resources - at play across these markets, and it constantly depends on who is talking to whom, during what activity, in what transaction, at what point in which personal trajectory. Our analysis of the metrolinguistic market place suggests we have to incorporate an understanding of the dynamics of linguistic repertoires, activities, objects and spatial repertoires in order to grasp the operation of any metrolingua franca.

If we ask what the lingua franca of such markets is, expecting an answer that identifies a recognizable code such as 'English', 'Cantonese', Arabic' and so on, we are looking in the wrong direction. In contexts of complex multilingual interaction a lingua franca is not some pregiven language but rather a constantly emergent set of 
linguistic possibilities. If we view lingua francas through the lens of modernist language ideology, where a lingua franca becomes a fixed, pre-existing language, we have put language as an entity before the process of communication. If, however, we view a lingua franca as an emergent mix that is always in flux - akin to the original meaning of the term and "its particular quality that each user thought that it was the other's language" (Walter (1988; p. 216, our translation), or Canagarajah's (2013) emphasis on Lingua Franca English (LFE) as a translingual practice rather than English as a Lingua Franca (ELF) as the use of a given code - then we can place the processes of interaction before an assumption about the medium. Just as Makoni and Pennycook (2012; Makoni, Makoni and Pennycook, 2010) argue that it may be more useful to think in terms of multilingua francas, suggesting that such language use is already made up of a mixture of linguistic resources, so we are making a case here for the idea of a metrolingua franca that draws on the spatial repertoire of the market.

\section{Conclusion: Emergent metrolingua francas}

When we ask how communication works across either Produce or Central Markets, it is clear, first of all, that it depends on who you ask. It might be tempting to opt for the easy explanation that, say, English is the default language of transaction and Cantonese the language of social interaction, or that workers at the Produce Market "use broken English and lingo in Lebanese", as Joseph puts it. But any such assumption clearly falls a long way short of describing the complexity here. The 
identification of Mandarin, Cantonese, Lebanese and English as potential lingua francas points to this already. Beyond this, however, none of these categories of language is at all stable: so-called Mandarin may be heavy with Cantonese or Hokkien elements. Cantonese may be quite 'Mando' (Mandarin-influenced, as one research assistant put it), mixed with Hakka, Hokkien or English, rural, regional, or urban, or a product of longer histories of migration and travel through Southeast Asia. Likewise, the identification of 'Lebanese' as the 'lingo' up by doors 1 and 2 of the Produce market conceals not only the diversity of forms of Arabic (there are speakers of other varieties, as well as Maltese), a range of varieties of English (not so much 'broken' as diverse) as well as other languages (Talib and Muhibb's workers are of Turkish, Pakistani, Moroccan, Sudanese-Egyptian, Somalian and Philippino backgrounds).

This does not mean, however, that if we could indeed record and analyse all the interactions of these markets, we could overcome this perspectival hurdle and identify the real lingua franca. At stake here is something more complex: People use and identify languages (they 'lingo' in Joseph's terms) according to a range of perceptions about their interlocutors, their own languages, and the transactions they are engaged in. It is clearly the case that there are cultural, culinary and ethnic ties - part of the broader histories and networks of growers and sellers, in relation to different waves of immigration (Italian, Maltese, Lebanese, Cantonese), linked to the need to grow one's own food (often for basic economic purposes, but also for culinary reasons), embedded within processes of marginalization and 
discrimination faced by various groups of migrants, as well as the informal economy and variety of forms of labour provided by market gardens and markets themselves. Yet these broad affiliations lead not so much to the creation of identifiable market lingua francas, but rather become significant contributors to the spatial resources of the market. As the young corn husker put it, in the market there are “也都有，撈埋一 齊” (all sorts of languages mixed together).

None of this can sit outside a consideration of the spatial repertoires of these markets, or the intersecting domains of mobilities, practices, spaces and subjects (Cresswell and Merriman, 2011). We have therefore stressed the need to understand the interaction between spatial and personal repertoires, as well as between multitasking and objects. The repertoires of linguistic resources that people bring from their historical trajectories intersect with the spatial organization of other repertoires, while the practices of buying and selling, bartering and negotiating, husking corn and stacking boxes, bring a range of other semiotic practices into play: yellowing zucchini (down goes the price) and yellowing mangoes (up goes the price), the personal repertoires, beliefs and expectations of interlocutors, the noise and urgency of market selling, the rhythm of the city (a midmorning slow sale at Central Market is very different from flogging off the celery at the end of the afternoon - "One dollar!! One dollar!! Yi kuai quan! Yi kuai quan!" - all play crucial roles in how various resources will be used and taken up, and therefore what constitute at any place and time the metrolingua franca of a market and the spatial repertoires from which it is drawn. A focus on metrolingua francas makes 
diversity our starting point (cf Otsuji and Pennycook, 2014), and the connection between language and the city central. Metrolingua francas are emergent from the contexts of interaction, drawing on the available resources of spatial repertoires.

\title{
Transcription Conventions
}

\begin{abstract}
Arabic utterances are phonemically transcribed (i.e. transliterated); Cantonese uses Cantonese characters and jyutping transliteration (see footnote 4)
\end{abstract}

\section{English translations provided in brackets}

\section{Exact data quotes are provided in "double quotes" in text}

\begin{tabular}{l|l}
\hline$?$ & Rising or question intonation \\
\hline$!$ & Animated tone; not necessarily a grammatical exclamation \\
\hline$:$ & Elongation \\
\hline$\ldots$ & Pause \\
\hline [word] & Paralinguistic features and situational descriptions
\end{tabular}

1 This can be dangerous work, too: During our period of research at this market, at 5:20 am on June 26, 2012, forklift driver Lilipe Manuoliku Hehea was killed when his forklift turned over in one of the loading areas. 
2 Ras and blue are a short form of 'raspberry' and 'blueberry'. Such terminology was common in our data - 'caulies' for cauliflower, 'rocky' for rockmelon, for example alongside alternations between mixed terms such as allettuce and khass (the lettuce/ lettuce). 3 Part of an Australian Research Council (ARC)-funded Discovery Project DP110101014, Metrolingual language practices in four urban sites: Talking in the city, chief investigators Alastair Pennycook and Emi Otsuji. We are indebted to our former project manager, Astrid Lorange, other research assistants, and our willing participants for all their assistance obtaining this data. The names of the markets and the people working there have been changed to protect anonymity.

${ }^{4}$ Both Arabic and Cantonese present particular difficulties here because of the large gap between spoken and written versions of the language and the lack of conventions for such transcriptions. After considerable discussions with our transcribers and other researchers, it was decided that using Arabic script presented too many obstacles in the representation of these spoken (Lebanese) Arabic examples and that Roman script was preferable (though also limited). Roman script is also commonly used amongst $2^{\text {nd }}$ generation LebaneseAustralians, such as Tabib, Muhibb and our transcriber. The Cantonese transcriptions, on the other hand, seemed to work better, even though the lack of established characters for spoken Cantonese made this a difficult task. We have used Chinese (Cantonese) characters and jyutping transliteration (favoured by the Linguistic Society of Hong Kong). We are also aware of the problem that using Roman script (rather than Arabic) for one and Chinese characters for the other, possibly presents the latter as more 'different' from English and other similarly-scripted languages. 


\section{References}

Ayoola, K (2009) Haggling exchanges at meat stalls in some markets in Lagos, Nigeria. Discourse Studies, 11(4): 387-400.

Block, D. (2014) Social class in applied linguistics. London: Routledge

Blommaert, J (2010) The sociolinguistics of globalization. Cambridge: Cambridge University Press.

Blommaert, J and A Backus (2011) Repertoires revisited: 'Knowing language' in superdiversity. Paper 67, Working Papers in Urban Language \& Literacies: Tilburg University.

Busch, B (2013) Mehrsprachigkeit. Wien: Facultas Verlags

Canagarajah, S (2013) Translingual practice: Global Englishes and cosmopolitan relations. New York: Routledge. 
Creese, A, and A Blackledge. (2011) Separate and Flexible Bilingualism in Complementary Schools: Multiple Language Practices in Interrelationship. Journal of Pragmatics 43: 1196-1208.

Cresswell, T and P Merriman (2011) Introduction: Geographies of mobilities practices, spaces, subjects. In T Cresswell and P Merriman (Eds) Geographies of mobilities: practices, spaces, subjects. Farnham: Ashgate, pp1-15.

Duchêne, A (2009) Marketing, management and performance: multilingualism as a commodity in a tourism call center. Language policy, 8(1) 27-50.

Edensor, T (2011) Commuter: Mobility, rhythm and commuting. In T Cresswell and P Merriman (Eds) Geographies of mobilities: practices, spaces, subjects. Farnham: Ashgate, pp 189-204.

Heller, M (2010) The commodification of language. Annual Review of Anthropology, $39,101-114$.

Heller, M and A Duchêne. (2011) Pride and profit: Changing discourses of language, capital and nation-state. In A Duchêne \& M Heller (Eds) Language in late capitalism: Pride and profit. London: Routledge. 1-21. 
Holmes, J, M Marra \& B King (2013) How permeable is the formal-informal boundary at work? An ethnographic account of the role of food in workplace discourse. In Cornelia Gerhardt, Maximiliane Frobenius and Susanne Ley (Eds) Culinary Linguistics: The Chef's Special. Amsterdam: John Benjamins, 191-209.

James, S (2008) Market gardens and McMansions: Contesting the concept of 'growth' on Sydney's peri-urban fringe. Online Proceedings of 'Sustaining Culture' Annual Conference of the Cultural Studies Association of Australia (CSAA) UniSA, Adelaide December 6-8, 2007 http://unisa.edu.au/com/csaa/onlineproceedings.htm

Kramsch, C and A Whiteside. (2008). Language ecology in multilingual settings. Towards a theory of symbolic competence. Applied Linguistics 29: 645-671

Leeman, J and G Modan. (2009). Commodified languages in Chinatown: a contextualized approach to linguistic landscape, Journal of Sociolinguistics 13 (3), $332-362$.

Li Wei. (2011) Moment Analysis and translanguaging space: Discursive construction of identities by multilingual Chinese youth in Britain. Journal of Pragmatics 43 $1222-1235$ 
Mac Giolla Chríost, D (2007) Language and the City, Basingstoke: Palgrave Macmillan.

Makoni, B, S Makoni and A Pennycook (2010) On speaking multilanguages: Urban lingos and fluid multilingualism. In P Cuvelier, T Du Plessis, M Meeuwis, R Vandekerckhove and V Webb (Eds) Multilingualism from below. Hatfirld, Pretoria, Van Schaik. (pp 147-165).

Makoni, S. \& A Pennycook (2012), 'Disinventing multilingualism: from monological multilingualism to multilingua francas' in Marilyn Martin-Jones, Adrian Blackledge and Angela Creese (eds), The Routlledge Handbook of Multilingualism, Routledge, New York, pp. 439-453.

Markus, A (1979) Fear and hatred: Purifying Australia and California 1850-1901. Sydney: Hale and Iremonger.

McGowan, B (2005) Chinese market gardens in southern and western New South Wales. Australian Humanities Review, 36, July 2005. Np http://www.australianhumanitiesreview.org/archive/Issue-July$\underline{2005 / 10 M c G o w a n . h t m l}$

Otsuji, E and A Pennycook. (2010) Metrolingualism: Fixity, fluidity and language in flux. International Journal of Multilingualism 7: 240-254. 
Otsuji, E and A Pennycook. (2014). Unremarkable hybridities and metrolingual practices. In R. Rubdy \& L. Alsagoff (Eds.), The Global-Local Interface, Language Choice and Hybridity. Bristol: Multilingual Matters.

Panayiotopoulos, P (2010). Ethnicity, migration and enterprise. Basingstoke: Palgrave Macmillan.

Park, J S-Y and L Wee (2012) Markets of English: Linguistic capital and language policy in a globalizing world. New York: Routledge

Pennycook A. (2010). Language as a local practice. London: Routledge.

Pennycook, A and E Otsuji (2014) Metrolingual multitasking and spatial repertoires: 'Pizza mo two minutes coming', Journal of Sociolinguistics, 18(2) 161-184.

Pennycook, A and E Otsuji. (In press). Metrolingualism: Language and the City. London: Routledge.

Rampton, B. (2007) Neo-Hymesian linguistic ethnography in the UK. Journal of Sociolinguistics 11(5): 584-608. 
Ribeiro, G L (2012) Conclusion: Globalization from below and the non-hegemonic world-system. In G Mathews, G L Ribeiro and C A Vega (Eds) Globalization from below: The world's other economy (pp 221-235) London: Routledge.

Walter, H. (1988). Le français dans tous les sens. Paris: Robert Laffont.

Watson, S. (2009). Brief encounters of an unpredictable kind: Everyday multiculturalism in two London street markets. In Wise A and S Velayutham (Eds) Everyday multiculturalism. Houndmills: Palgrave Macmillan. 125-139.

Williams, M (nd) Wading 10,000 li to seek their fortune. 東華新報 - Tung Wah News selections 1898-1901. Chinese Heritage of Australian Federation Project www.chaf.lib.latrobe.edu.au

Wise, A. (2009). Everyday multiculturalism" Transversal crossings and working class cosmopolitans. In Wise A and S Velayutham (Eds) Everyday multiculturalism. Houndmills: Palgrave Macmillan. 21-45.

Wise, A and S Velayutham. (2009). Introduction: Multiculturalism and everyday life. In Wise A and S Velayutham (Eds) Everyday multiculturalism. Houndmills: Palgrave Macmillan. 1-17.

Wood, P and C Landry. (2008). The intercultural city. London: Earthscan. 


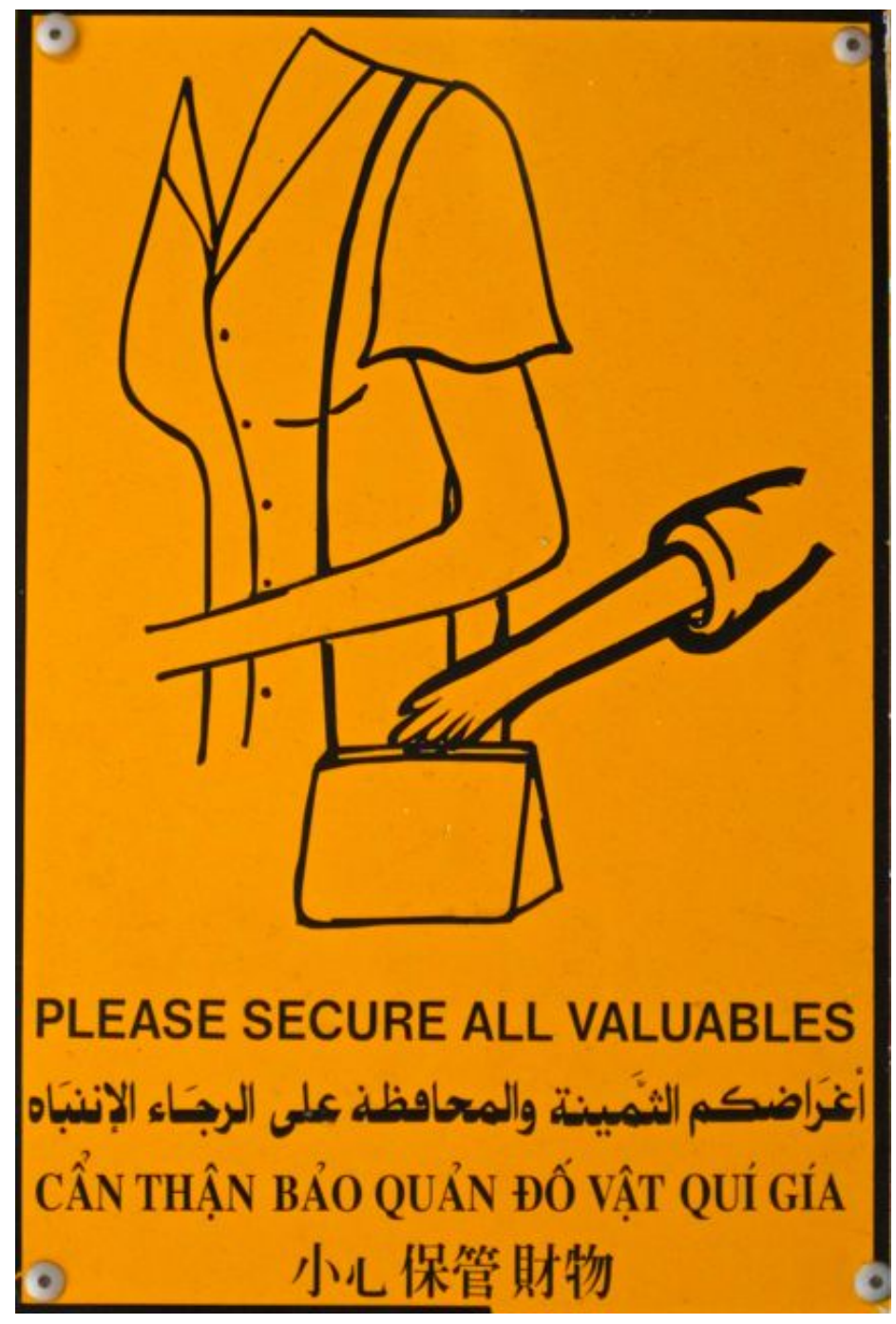

Figure 1: Public sign 